\title{
Estimation of daily vertical solar irradiation by the use of meteorological data
}

\author{
Mourad Benziane, Mouloud Ayad, Kamel Saoudi, Mohamed Rezki \\ Department of Electrical Engineering, Faculty of Science and Applied Science, \\ LPM3E Laboratory, University of Bouira, Algeria
}

\begin{abstract}
Article Info
Article history:

ABSTRACT

Received Sep 17, 2018

Revised Dec 10, 2018

Accepted Dec 28, 2018

Keywords:

Artificial neural networks

Photovoltaic

Renewable energy

Vertical solar irradiation (VSI)

Energy has been recognized as one of the most inputs for social and economic improvement and a clean energy is a challenge in the future. Therefore, renewable energy has become one of the most popular sources of energy. The solar energy, is one of this renewable energy, has the most propriety which is the durability. Due to its geographical location, Algeria has one of the world's most important gas reserves, and has in addition one of the highest solar reservoirs in the world. Solar irradiation is an essential parameter for many applications such as the design and performance of renewable energy systems, but this is not always available, especially in remote locations. The prediction of solar irradiation values is often the only practical way to acquire these data. The objective of this work is to develop a model for the prediction of the Vertical Solar Irradiation (VSI) based on real meteorological data. This model is based on the Artificial Neural Networks (ANN).
\end{abstract}

Copyright $(2019$ Institute of Advanced Engineering and Science. All rights reserved.

\section{Corresponding Author:}

Mourad Benziane,

Department of Electrical Engineering, Faculty of Science and Applied Science,

University of Bouira,

Rue DRISSI Yahia - Bouira 10000 - Algeria.

Email: benzianemourad@yahoo.fr

\section{INTRODUCTION}

Nowadays, the consumption of the energy is very important and still increase. And the consequence is the exhausting of the traditional sources of the energy. So the need of a new energy source is very necessary. The main renewable energy sources are the sun, wind, biomass, tides and waves of seas. The solar energy, is one of this renewable energy, has the most characteristics which is the durability. Therefore, many countries in the world have shifted to this environment friendly alternative energy resources and the renewable energy has become one of the most popular sources of energy. For example, Algeria started paying more attention to green energy through an ambitious program of renewable energy development. The updated program of renewable energy is to install a renewable power about $22000 \mathrm{MW}$ in the horizon of 2030 for the domestic consumption. $37 \%$ of installed capacity until 2030 and $27 \%$ of the electricity production destined for the domestic consumption will be from renewable sources [1].

View of its geographical location, Algeria has one of the highest solar deposits in the world. Sunshine duration of almost all the national territory exceeds 2000 hours annually and can reach 3900 hours (High Plateaus and Sahara).The annual energy received on a horizontal surface of $1 \mathrm{~m}^{2}$ is nearly $3 \mathrm{KWh} / \mathrm{m}^{2}$ in the north and exceeds $5.6 \mathrm{KWh} / \mathrm{m}$ in the Great South [1]. The Algerian state clearly understood the issue of energy, this explains the reason for its launch into renewable energy (especially wind and solar), taking advantage of its natural potential and geostrategic position [2, 3]. The installation of solar energy systems requires information about global solar irradiation in the region where the system is to be installed. However, 
this information is not always available, especially in isolated areas. Therefore, predicting solar irradiation values is often the only practical way to acquire this information.

The traditional and most appropriated method of determining the intensity of solar irradiation is to install pyranometers in as many locations as possible, and this need times and increasing the cost of the installation. However, empirical methods that employ meteorological measures and factors, such as air temperature, sunshine duration, humidity, vapor pressure, and wind speed, are regularly used to overcome these observational difficulties.

Several studies have been proposed in the last decades and added to more conventional ones for predicting solar irradiation values [4-8]. Since each technique has different theoretical basis, the obtained results are also usually different. Some techniques may be more suitable than others for a specific system or component. The use of the Artificial Neural Networks (ANN) technique has shown its efficiency to solve complex nonlinear problems, especially as an estimation tool for predicting desired parameters from inputs without a known relation [9]. Prediction based on ANN technique has been used to solve several problems related to renewable energy and photovoltaic systems i.e. the estimation of the optimum tilt angle of photovoltaic panel in order to obtain the maximum of solar energy [10], the prediction of next day produced power [11]. The objective of this work is to propose an approach for the Vertical Solar Irradiation (VSI) prediction based on an ANN model by the use of meteorological measures.

\section{SOLAR POTENTIAL IN ALGERIA}

Algeria is endowed with a high solar potential. As can be deduced from Table 1, the yearly mean sunshine duration varies from a low of $2650 \mathrm{~h}$ on the coastal area to $3500 \mathrm{~h}$ in the Sahara (South). The potential of daily solar energy is important. It varies from a low average of $4.66 \mathrm{kWh} / \mathrm{m}^{2}$ in the north to a mean value of $7.26 \mathrm{kWh} / \mathrm{m}^{2}$ in the south. It means that the yearly energy potential on $86 \%$ of the territory is of the order of $2650 \mathrm{kWh} / \mathrm{m}^{2}$. The annual average daily sums of solar radiation that can be utilized for photovoltaic applications in Africa are shown in Figure 1. These values range from 3000-7000 Wh/m2/day [3].

Table 1. Solar Potential in Algeria [12]

\begin{tabular}{ccccc}
\hline Areas & Coastal area & High plateau & Sahara & Total \\
\hline Surface $(\%)$ & 4 & 10 & 86 & 100 \\
Area $\left(\mathrm{Km}^{2}\right)$ & 95,270 & 238,174 & $2,048,297$ & $2,381,741$ \\
Average duration of sunshine (h/year) & 2650 & 3000 & 3500 & \\
Received average energy $\left(\mathrm{KWh} / \mathrm{m}^{2} /\right.$ year $)$ & 1700 & 1900 & 2650 & \\
Potential daily energy $(\mathrm{TWh})$ & 443.96 & 1240.89 & $14,870.63$ & $16,555.48$ \\
\hline
\end{tabular}

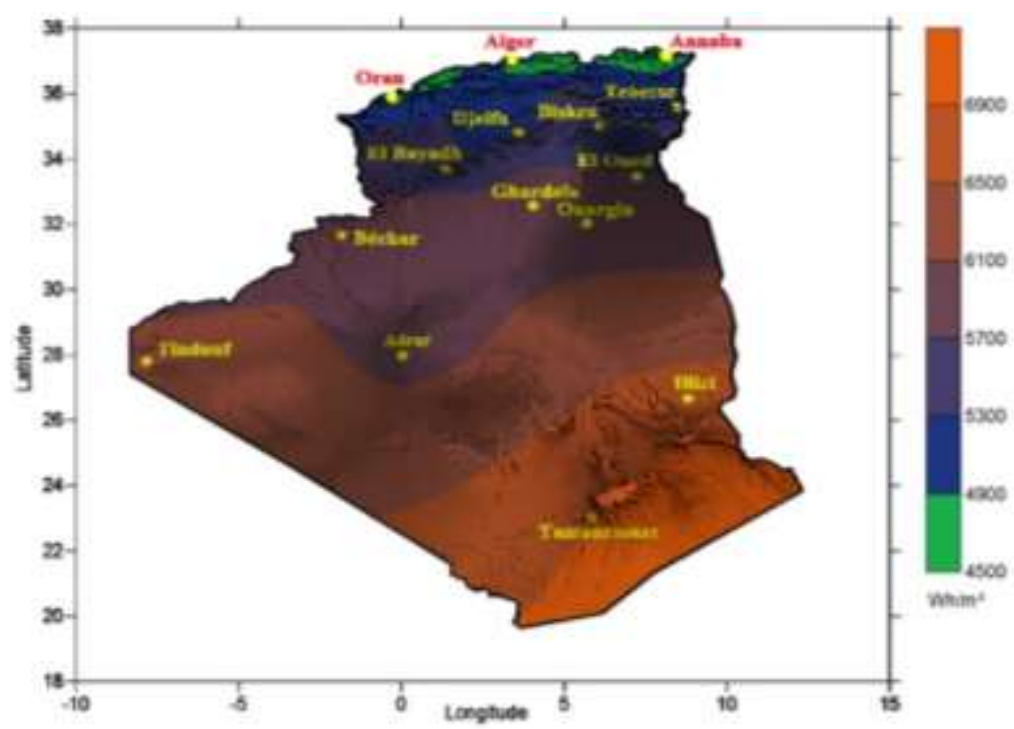

Figure 1. Annual mean global radiation received on a horizontal surface [13] 


\section{RESULTS AND ANALYSIS}

\subsection{Artificial neural networks for prediction vertical solar irradiation}

The choice of the ANN technique is due to its ability to learn from previous experiences of a natural phenomenon. The learning is done from the examples that form the database and allows to build a mathematical model linking the output to the inputs [14].

ANNs consist of connected elementary processors operating in parallel called neurons. Each processor calculates a single output based on the information it receives. Each neuron-neuron bond is associated with a weight. The development of a neural network is done in two stages, the choice of the architecture and the identification of the parameters. This phase known as learning it consist of the identification of the model parameters, by an iterative method of modifying the connections weights. The most studied ANN architecture is the multi-layer neural network (or Multi-Layer Perceptron MLP). It consists of neurons distributed over several layers, the neurons of which are all connected to the neurons of the adjacent layers. Layers between the input and output are called "hidden layers" [15, 16].

It is capable to model any linear and nonlinear systems by using an input layer; hidden layer (s) and an output layer [17]. Prediction of the vertical solar irradiation can be addressed using the MLP. Figure 2 shows this type of architecture: inputs (Meteorological data), a hidden layer and an output layer with one neuron.

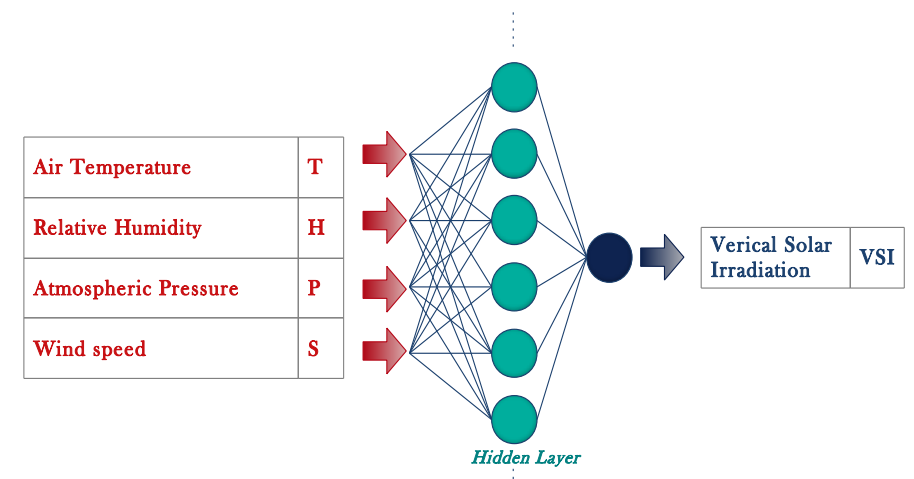

Figure 2. MLP with one hidden layer

Mathematically, if the nonlinear transformation $f$ is identical for all neurons, the expression of the output of the MLP with one hidden layer is given by:

$$
h_{j}=\sum w_{j i} x_{i}+w_{j 0} \quad \text { And } \quad y(x)=f\left(\sum_{j=1}^{H} W_{j} h_{j}+W_{0}\right)
$$

$w_{j i}$ are the weights between the inputs and the hidden layer and $\mathrm{Wj}$ are the weights between the hidden layer and the output layer.

The activation function $f$ can be anyone, but in practice and in particular when performing supervised learning, it is necessary to have a continuous and completely differentiable function. There are several activation functions. In this study our choice is a sigmoid function for hidden layers. Supervised learning consists in determining the network weights which minimize on all the data of the learning dataset, the deviations between the output values (measured values) and the computed output values by the network. The objective of learning is to find the minimum of the quadratic criterion:

$$
C(\bar{w}, \bar{W})=\frac{1}{N} \sum_{i=1}^{N}\left(t_{i}-y_{i}\right)^{2}
$$

where $\mathrm{N}$ is the number of examples of the learning dataset, $W$ and $w$ are the vectors of the weights of the two layers. 
The method traditionally used to perform supervised learning of the network is the back-propagation algorithm, so called because of the typical way of calculating derivatives of successive layers starting from the output layer to go up to the input layer. Initially, the algorithm uses the non-linear gradient optimization method. Among the best known are the Quasi-Newton method and Levenberg-Marquardt which is used in our study $[15,17,18]$.

\subsection{Database}

The database used in this work is composed of mean daily values of: vertical solar irradiation VSI, relative humidity $\mathrm{H}$, air temperature $\mathrm{T}$, atmospheric pressure $\mathrm{P}$ and wind speed $\mathrm{V}$, covering more than three years meteorological data $(01 / 01 / 2002$ to $03 / 15 / 2005)$ at Bouira (latitude 36.383, longitude 3.892). This database contains 1170 vectors, 970 vectors are used for learning and 200 vectors for testing. Figure 3 shows the variation of Air temperature $(\mathrm{T})$ and vertical solar irradiation VSI.
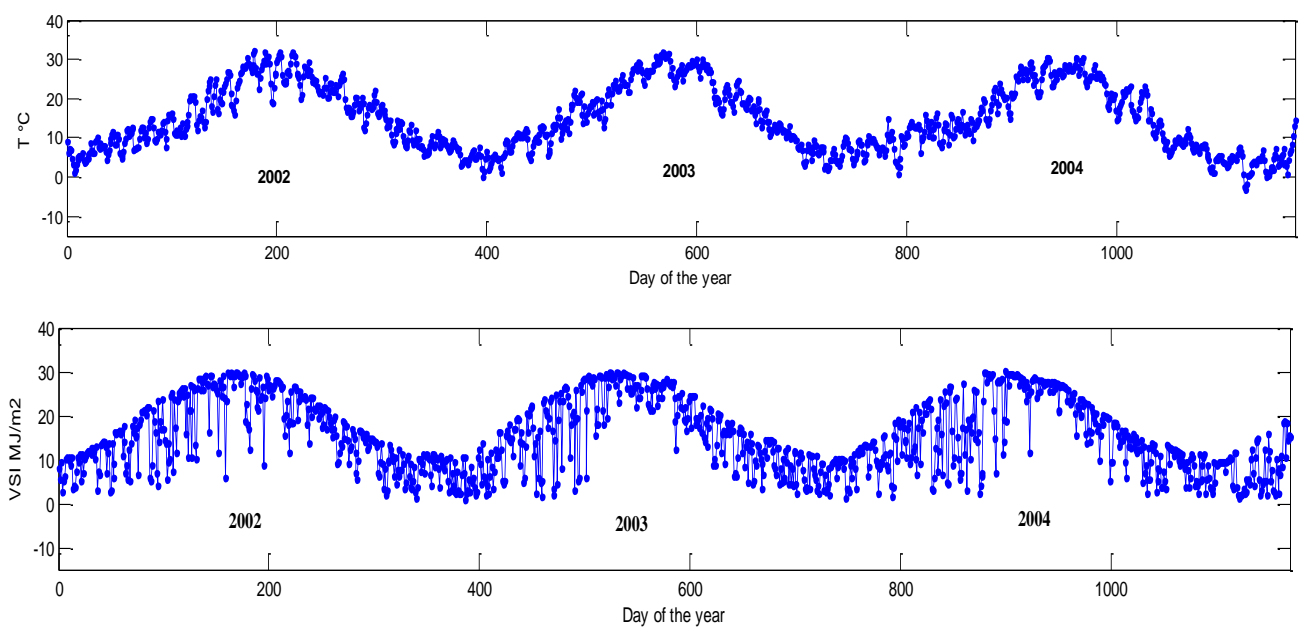

Figure 3. Variation of air temperature (T) and vertical solar irradiation (VSI)

\subsection{Performance evaluation}

In order to find the best ANN model, several architectures have been tested. The evaluation is made according to the most used error criteria in literature: mean square error MSE, mean absolute error MAE and root mean square error RMSE.

$$
\begin{aligned}
& M S E=\sum_{i=1}^{N}\left(\left|V S I_{i, m}-V S I_{i, p}\right|\right)^{2} / N \\
& M A E=\sum_{i=1}^{N}\left|V S I_{i, m}-V S I_{i, p}\right|^{2} / N \\
& R M S E=\left[\sum_{i=1}^{N}\left(\left|V S I_{i, m}-V S I_{i, p}\right|\right)^{2} / N\right]^{1 / 2}
\end{aligned}
$$

where $\mathrm{N}$ is a number of samples, $V S I_{m}$ and $V S I_{p}$ are the measured and predicted values of vertical solar irradiation respectively.

A second evaluation is done using the relative error (RE) in order to know the recognition rate of estimated values at each ANN and for different RE values. Table 2 shows the obtained results.

$$
R E_{i}=\left(\left|V S I_{i, m}-V S I_{i, p}\right| / V S I_{i, m}\right) \cdot 100 \%
$$


Table 2. Performance Evaluation of Different ANN Architectures

\begin{tabular}{ccccccccccc}
\hline $\mathrm{N}^{\circ}$ & Architecture & MSE & MAE & RMSE & & \multicolumn{5}{c}{ Relative Error (RE) } \\
& & & & & & $2 \%$ & $\leq 5 \%$ & $\leq 10 \%$ & $\leq 15 \%$ & $\leq 20 \%$ \\
$\leq 30 \%$
\end{tabular}

We note that the best results are obtained for the first and the fifth architectures, as shown in Figure 4 and Figure 5 respectively.

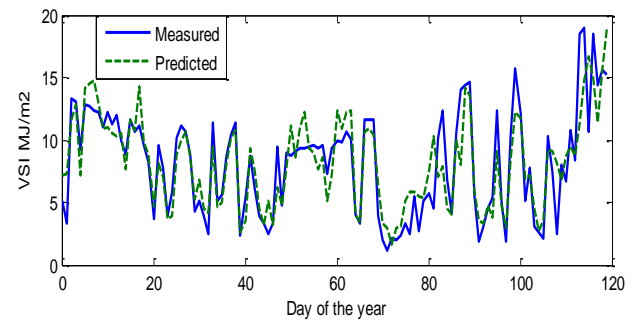

Figure 4. Predicted and measured on testing data using the first model

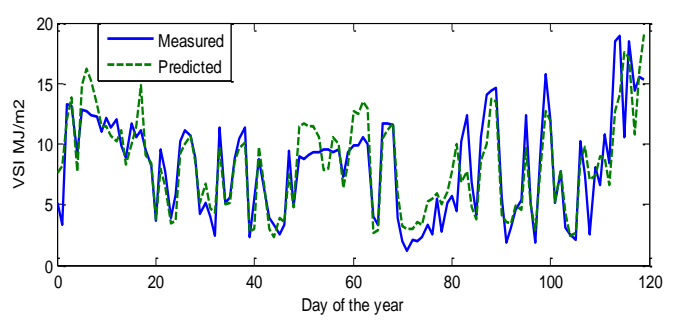

Figure 5. Predicted and measured on testing data using the fifth model

\section{CONCLUSION}

It is the great interest of solar energy that we tried in this paper to present our application. Continuous measurement of (VSI) is sometimes impossible especially in remote locations, hence the need to use different prediction techniques. In this article, we have proposed a prediction models based on ANN, learning is performed using a real database. The obtained results confirm the capability of the used technique for such applications, the improvement of these results can be achieved by using richer data bases or by using other techniques for constructing prediction models.

\section{REFERENCES}

[1] MEM, (Ministry of Energy and Mining), 2017.

Website: http://www.energy.gov.dz/francais/uploads/2016/Energie/energie-renouvelable.pdf.

[2] M. Rezki, M. Ayad, T. Benabdallah, "Opportunities of the Silicon Technology in Algeria", Int. Jour. Resea. in Engin. and Sci. (IJRES), vol. 1, no. 1, pp. 01-04, 2013.

[3] M. Ayad, M. Rezki, K. Saoudi, M. Benziane, Dj. Chikouche, "Estimation of Solar Radiation Received on a horizontal surface: a case study in Bouira", Jour. of Auto.\& Sys. Engin., vol. 10, no. 4, pp. 213-220, 2016.

[4] Haiying Dong, Lei Yang, Shengrui Zhang, Yuan Li, "Improved Prediction Approach on Solar Irradiance of Photovoltaic Power Station", TELKOMNIKA Indonesian Journal of Electrical Engineering, vol.12, no.3, pp. 17201726, Mar. 2014.

[5] Mustapha Elyaqouti, Lahoussine Bouhouch, Ahmed Ihlal, "Modelling and Predicting of the Characteristics of a Photovoltaic Generator on a Horizontal and Tilted Surface", International Journal of Electrical and Computer Engineering (IJECE) Vol. 6, No. 6, pp. 2557-2576, Dec. 2016.

[6] K. Dahmani, R. Dizene, G. Notton, C. Paoli, C. Voyant, M.L. Nivet, "Estimation of 5-min time-step data of tilted solar global irradiation using ANN (Artificial Neural Network) model," Energy, vol. 70, no. 1, pp. 374-381, June 2014.

[7] J.L. De Souza, G.B. Lyra, C.M. Dos Santos, R.A.F. Junior, C. Tiba, G.B. Lyra, M.A.M. Lemes, "Empirical models of daily and monthly global solar irradiation using sunshine duration for Alagoas State, Northeastern Brazil," Sustainable Energy Technologies and Assessment, vol. 14, pp. 35-45, April 2016.

[8] A. Boilley, L. Wald, "Comparison between meteorological re-analyses from ERA-Interim and MERRA and measurements of daily solar irradiation at surface," Renewable Energy, vol. 75, pp. 135-143, 2015.

[9] R. Muhammad Ehsan, S. P. Simon, and P. R. Venkateswaran, "Day-ahead forecasting of solar photovoltaic output power using multilayer perceptron," Neural Computing and Applications, vol. 28, no. 12, pp. 3981-3992, Dec 2017.

[10] K. Parkavi Kathirvelu, B. Viswanathan, "Estimation of Optimum Tilt Angle of PV Panel for Maximum Energy Harvesting," International Journal of Electrical and Computer Engineering, vol. 6, no. 5, pp. 2005-2024, 2016. 
[11] Mohammad H. Alomari, Jehad Adeeb, and Ola Younis, "Solar Photovoltaic Power Forecasting in Jordan using Artificial Neural Networks," International Journal of Electrical and Computer Engineering, Vol. 8, no. 1. pp. 497504, 2018.

[12] T. Boukelia, M.S. Mecibah, "Parabolic trough solar thermal power plant: Potential, and projects development in Algeria", Renewable and Sustainable Energy Reviews, vol. 21, pp. 288-297.May 2013.

[13] CDER, Centre de Développement des Energies Renouvelables (www.cder.dz), 2017 http://portail.cder.dz/IMG/jpg/carte_solaire_irradiation_globale_surface_horizontale_algerie.jpg

[14] S. Rehman and M. Mohandes, "Artificial neural network estimation of global solar radiation using air temperature and relative humidity," Energy Policy, vol. 36, pp. 571-576, 2008.

[15] M. Benziane and M. Bouamar, "A soft sensor development with dsPIC implementation for water quality monitoring," J. Automation \& Systems Engineering, vol. 10, no. 3, pp. 180-186, 2016.

[16] C. Renno, F. Petito, A. Gatto, "Artificial neural network models for predicting the solar radiation as input of a concentrating photovoltaic system," Energy Conversion and Management, vol. 106, pp. 999-1012, 2015.

[17] N. Kumar, S. P. Sharma, U. K. Sinha, Y. Nayak, "Prediction of Solar Energy Based on Intelligent ANN Modeling," International Journal of Renewable Energy Research, vol. 6, no. 1, pp. 183-188, 2016.

[18] O. Assas, H. Bouzgou, S. Fetah, M. Salmi and A. Boursas, "Use of the artificial neural network and meteorological data for predicting daily global solar radiation in Djelfa, Algeria," 2014 International Conference on Composite Materials \& Renewable Energy Applications (ICCMREA), Sousse, 2014, pp. 1-5.

\section{BIOGRAPHIES OF AUTHORS}

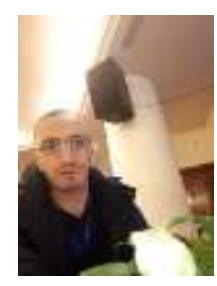

Mourad Benziane received his engineering and Magister degrees in electronics from the University of M'sila, Algeria in 2002, 2007 respectively. He is currently an Assistant Professor of electrical engineering at the Department of Electrical Engineering, University of Bouira, Algeria. He is a member in LPM3E Laboratory, University of Bouira, Algeria.

Her research interests cover digital signal processing, telecommunications and embedded systems.

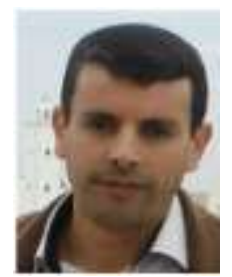

Mouloud Ayad received his engineering, Magister and Ph.D. degrees in electronics from the University of Setif1, Algeria in 2001, 2005 and 2015 respectively. He is currently an Assistant Professor of electrical engineering at the Department of Electrical Engineering, University of Bouira, Algeria. He is a member in LPM3E Laboratory, University of Bouira, Algeria. His research interests cover signal processing, Telecommunication systems and renewable energies.

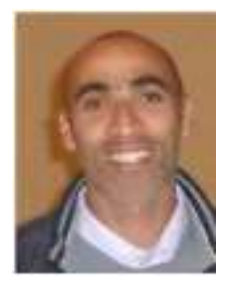

Kamel Saoudi received his bachelor, M.Sc. and Ph.D. degrees all in electrical engineering from the University of Sétif 1, in 2005, 2008 and 2014 respectively. He is currently an assistant professor at the Bouira University, Algeria. His research interests include robust nonlinear adaptive control, intelligent control, fuzzy control, power systems and renewable energy.

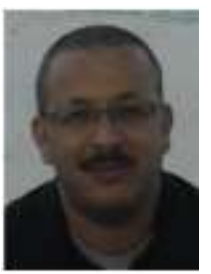

Mohamed Rezki received his engineering degrees in electronics from the University of Oran, Algeria in 1992 and Magister in electronics from the University of Saida, Algeria in 2006. And He received his Ph.D. degree in electronics from the University of Oran, Algeria in 2014.

Currently $\mathrm{He}$ is an Assistant Professor at the University of Bouira, Algeria. His main research is about digital signal processing, biomedical systems and electronic systems. 